\title{
Mining-Induced Stress-Fissure Field Evolution and the Disaster-Causing Mechanism in the High Gas Working Face of the Deep Hard Strata
}

\author{
Litong Dou $\mathbb{D}^{1,2,3}$ Ke Yang $\mathbb{D}^{1,2,3}$ Wenjie Liu $\mathbb{D}^{1,2,3}$ and Xiaolou Chi $\mathbb{D}^{1,2,3}$ \\ ${ }^{1}$ State Key Laboratory of Mining Response and Disaster Prevention and Control in Deep Coal Mines, Anhui University of Science \\ and Technology, Huainan 232001, China \\ ${ }^{2}$ National \& Local Joint Engineering Research Center of Precision Coal Mining, Anhui University of Science and Technology, \\ Huainan, 232001 Anhui, China \\ ${ }^{3}$ Key Laboratory of Mining Coal Safety and Efficiently Constructed by Anhui Province and Ministry of Education, Anhui University \\ of Science and Technology, Huainan 232001, China
}

Correspondence should be addressed to Ke Yang; keyang2003@163.com

Received 16 July 2020; Revised 23 August 2020; Accepted 31 August 2020; Published 29 September 2020

Academic Editor: Zhijie Wen

Copyright (c) 2020 Litong Dou et al. This is an open access article distributed under the Creative Commons Attribution License, which permits unrestricted use, distribution, and reproduction in any medium, provided the original work is properly cited.

\begin{abstract}
The compound dynamic disaster of coal and gas outbursts and rockburst is a typical hazard jeopardizing the mining of the high gas content coal seam under a hard roof condition. In this study, the hard roof s mechanism inducing this hazard is analyzed. Physical analog modeling experiments and in situ monitoring of mining-induced stress were performed during coal seam mining under a hard roof condition. The pattern of hard roof breakage effect on the stress-fissure field evolution was revealed. The elastic energy was released and propagated on both sides immediately after the hard roof breaking, leading to energy accumulation. Meanwhile, expansive roof collapse resulted in the intense weighting of the working face and rockburst. Thus, the coal and gas outburst occurred under the joint action of the impact energy generated by breaking the hard roof and gas expansion energy. In other words, the compound dynamic disaster happened. Synergistic stereoextraction integrating cross-seam drilling and along-seam drilling was combined with deep hole advanced presplitting blasting technology to cope with the compound dynamic disaster in the high gas coal seam under a hard roof condition.
\end{abstract}

\section{Introduction}

Rockburst and coal and gas outbursts are the most severe dynamic disasters occurring in coal mining. In China, coal seams are usually featured by complex geological conditions and faced with the challenge of severe coal and gas outbursts and rockburst disasters [1]. These disasters have become the major restricting factors for the safe and high-efficiency mining of coal resources [2]. The coal and gas outbursts in some deep mines of China are even more complicated, manifesting obscure features [3]. There are some common features between the coal and gas outburst and rockburst, and they cannot be plausibly explained by the conventional theory of coal and gas outburst or rockburst [4]. The interaction between the two disasters becomes even more significant in deep mining, leading to compound dynamic disasters. Due to the coupling of multiple factors during the compound dynamic disasters, coal and gas outbursts and rockburst may become mutually precipitating and strengthening factors in the genesis, occurrence, and development of the coal mine incidents [5]. Such interactions add to the difficulty in the understanding of the occurrence mechanism. The compound dynamic disaster in the coal mines results from the joint action of high ground stress in deep positions, high gas pressure [6], hard roof, low-permeability coal bodies, and other engineering [7] and geological factors. Such disasters seem inevitable as coal extraction goes deeper, bringing about new challenges for disaster prevention and management [8]. In recent years, many researchers worldwide have investigated the occurrence mechanism of compound dynamic 
disasters of coal and gas outbursts and rockburst and the disaster-causing mechanism of a hard roof.

Petukhov [9] proposed integrating studies of rockburst and coal and gas outburst as two separate but correlated phenomena. Zhang et al. [10] were the first to propose a uniform instability theory concerning rockburst and coal and gas outbursts. They provided the criteria for the occurrence of rockburst and coal and gas outbursts. It was suggested that the outburst of gas exceeded coal and gas outburst, while rockburst was accompanied by zero or very little outburst of gas. Therefore, rockburst was also known as the outburst of coal; the term outburst is specifically referred to as the rockburst with the gas outburst only. $\mathrm{Li}$ et al. $[11,12]$ assumed that the rockburst was closely related to gas under deep mining conditions. High-pressure gas was very likely to be involved in the genesis of rockburst. The rockburst could be induced by the coupling of excavation unloading of the gas-containing porous media and gasbearing structures and desorption and expansion of gas adsorbed under high pressure. Pan et al. [13] reported that in a high gas coal mine, increasing the gas extraction volume to induce gas desorption, seepage, and discharge in large amounts from the coal seam would change the physical properties of coal bodies. Thus, gas disasters were transformed into rockburst disasters, accompanied by increased intensity and rockburst frequency. The primary mechanism, by which a hard roof induces rockburst, is related to the stress concentration due to a hanging roof and coal and rock failure caused by shock bump under roof breaking. Such failure can directly lead to rockburst and other types of disasters, such as water bursting in mine, coal and gas outburst, and roof caving [14-16]. Lurka [17] employed the tomographic imaging technique to quantify the risk of rockburst caused by roof breaking in the longwall face of the Zabrze Bielszowice coal mine in Poland. They also delineated the risk area using the same technology. Dou et al. [18] revealed the dynamic and static load superposition principle in coal mines' rockburst through theoretical and experimental studies. They further discussed the methods of rockburst monitoring, prevention, and control. Yang and Zhen [19] studied the characteristics of overburden movement in mechanized top caving mining of thick coal seams and mechanism of coal-rock dynamic disasters caused by the superposition of static and dynamic loads.

There seems to be a growing awareness of the connections between rockburst and coal and gas outburst in coal mines as more studies have been done concerning these disasters' occurrence mechanism. However, the transformation pattern and mechanism between the two disasters remain unclear. There is still a lack of consensus on the hard roof s mechanism inducing rockburst and coal and gas outbursts. To reveal the compound dynamic disaster's occurrence mechanism, we need to study the stress evolution and the deformation and failure features of the surrounding rocks under a hard roof condition. Here, the A3 coal seam of the Paner Coal Mine's mining conditions was taken as the project background. A physical analog modeling experiment on the stress-fissure field evolution in thick coal seam mining and in situ monitoring of mining-induced stress was performed under a hard roof condition. The hard roof's stress distribution and deformation features upon breaking and the hard roof mechanism inducing the compound dynamic disaster were analyzed in detail.

\section{Project Overview}

2.1. Geological Conditions. The A3 coal seam of the 11223 working face of Paner Coal Mine in Huainan has elevation from -460.0 to $-500.0 \mathrm{~m}$; the layout of the working face is shown in Figure 1. The coal seam thickness range is 2.09 to $7.91 \mathrm{~m}$, the average being $5 \mathrm{~m}$. The coal seam has a simple structure and rarely contains the dirt bands. The average dip angle of the stratum is $13^{\circ}$. The roof of the coal same is the directly overlying fine sandstone old roof, in the grayish-white color, and contains quartz predominantly. The roof has a fine-grained structure and a thickness of $8.3 \sim 20.9 \mathrm{~m}$, the average being $14.6 \mathrm{~m}, f=5.88$. The direct floor of the coal seam is the mudstone, with an average thickness of $1.5 \mathrm{~m}$. The rock column diagram of the stratum is shown in Figure 2. The 11223 working face extends for $180 \mathrm{~m}$ in length, and the longwall fully mechanized fullseam mining is performed along the strike. The elevations of the ventilation roadway and transportation roadway are $-460.1 \sim-498.6 \mathrm{~m}$ and $-500.1 \sim-554.8 \mathrm{~m}$, respectively. The fully caving method is used for roof management. The full strike length of the working face is $1466 \mathrm{~m}$.

The 11223 working face is located in the risk area of gas outbursts, mainly in the A3 coal seam. It is estimated that the absolute volume of outburst gas is $36.41 \mathrm{~m}^{3} / \mathrm{min}$ during stoping. The entire A3 coal seam is prone to spontaneous combustion. The maximum comprehensive gas pressure of the A3 coal seam is $2.6 \mathrm{MPa}$, the maximum gas content is $11.19 \mathrm{~m}^{3} / \mathrm{t}$, and the gas gradient is $6.67 \mathrm{~m}^{3} / \mathrm{t}$. The gas content varies quickly with elevation. The gas permeability coefficient of the A3 coal seam is $0.23 \mathrm{~m}^{2} /\left(\mathrm{MPa}^{2} \cdot \mathrm{d}\right)$.

2.2. Disaster Manifestations. The 11223 working face is overlain by two layers of thick hard rock strata. Above the coal seam, the hard roof exerts a clamping load on the coal bodies when forming a hanging roof, which increases stress concentration in coal bodies. Moreover, the shock bump produced by roof breaking can be transferred to the coal bodies in the roadway, leading to strong ground pressure. The working resistance of the support upon the initial weighting of the working face increases abruptly. The phenomena of leaky roof and spalling occur on the coal wall side, giving rise to a high risk of impact for the coal bodies (as shown in Figure 3). The leaky roof problem is particularly severe when the 11223 working face advances to $54 \mathrm{~m}$.

The 11223 working face is located within the risk area of the outburst. The A3 coal seam is the outburst coal seam, where 14 coal and gas outbursts occurred during the shaft construction. Ten outbursts occurred in the A4 coal seam, and the elevation of the initial outburst was $-385 \mathrm{~m}$. One outburst occurred in the A3 coal seam, with an elevation of $-522 \mathrm{~m}$. These outbursts generally occurred when tectonic belts were encountered during cross-cut coal uncovering 

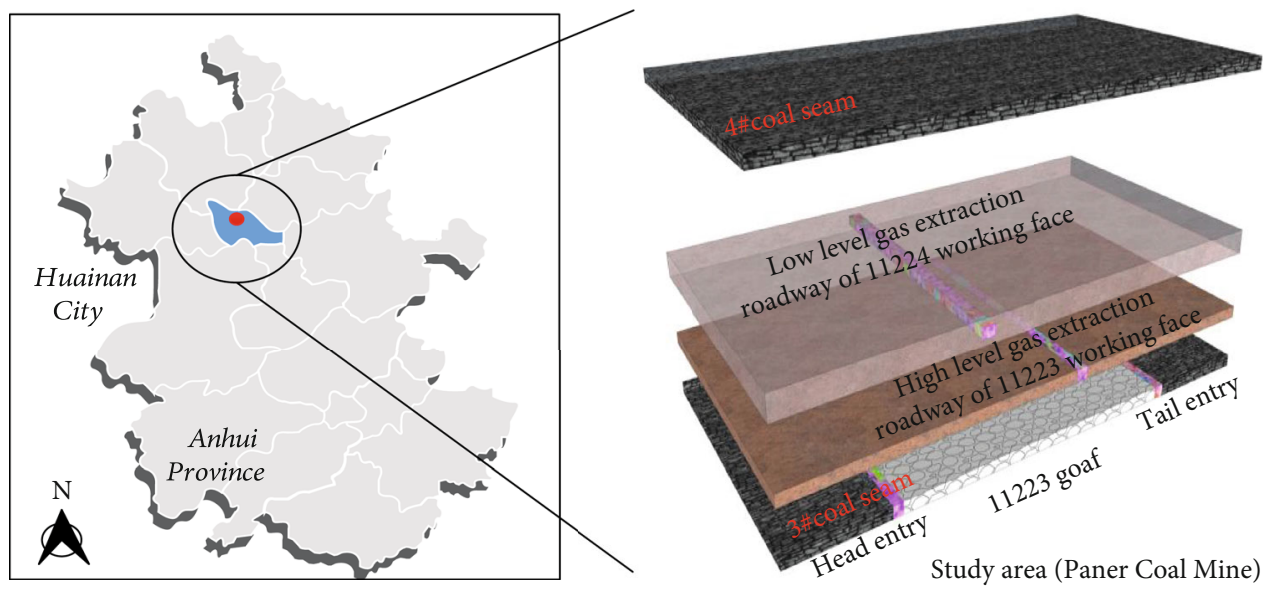

Figure 1: The layout of the working face.

\begin{tabular}{|c|c|c|c|}
\hline$\frac{8}{3 / 3}$ & Lithology & Thickness/(m) & Lithologic characteristics \\
\hline & 4 \#coal & 3.0 & Mainly black, massive and scaly, mainly semi-bright \\
\hline- & $\begin{array}{c}\text { Sandy } \\
\text { mudstone }\end{array}$ & 6.6 & Dark gray, dense, sandy muddy structure \\
\hline & Gritstone & 12.8 & Gray-white, dense, medium-fine structure \\
\hline & Mudstone & 2.8 & Gray, muddy structure \\
\hline & $\begin{array}{c}\text { Fine } \\
\text { sandstone }\end{array}$ & 12.0 & Gray-white, fine-grained \\
\hline & $\begin{array}{c}\text { Sandy } \\
\text { mudstone }\end{array}$ & 2.2 & Dark gray, sandy argillaceous structure, visible thin mudstone \\
\hline - & $\begin{array}{c}\text { Fine } \\
\text { sandstone }\end{array}$ & 14.6 & Light gray, fine-grained, complete layer \\
\hline & $\begin{array}{c}\text { Sandy } \\
\text { mudstone }\end{array}$ & 5.0 & Dark gray, sandy muddy structure, dense \\
\hline & 3 \#coal & 5.0 & Mainly black, massive and scaly, mainly semi-bright \\
\hline- & Mudstone & 1.5 & Grayish black, sandy muddy structure, visible \\
\hline & $1 \#$ coal & 3.5 & Mainly black, massive and scaly, mainly semi-bright \\
\hline & Mudstone & 2.2 & Grayish black, sandy muddy structure, visible \\
\hline
\end{tabular}

FIgURE 2: The rock column diagram of the stratum.

and tunneling of the working face. The coal and gas outbursts during the shaft construction of Paner Coal Mine are shown in Table 1.

As coal mines are getting deeper each year, they experience the interaction of such complex factors as high crustal stress, high gas, high anisotropy, and low permeability. Consequently, the scopes of the two dynamic disasters keep expanding. Since higher elastic energy and internal energy of coal gas accumulate in deeper coal and rock masses, the latter get closer to the threshold for the transition from steady state to nonsteady one. In that case, outbursts and impact become mutually disturbing and precipitating factors. The conditional threshold for dynamic disasters drops compared to that of pure rockburst or coal and gas outburst, while the disaster intensity increases. Based on the above, the existing predictors for a single dynamic disaster may fail, and new challenges occur concerning the prevention and management of dynamic disasters. 

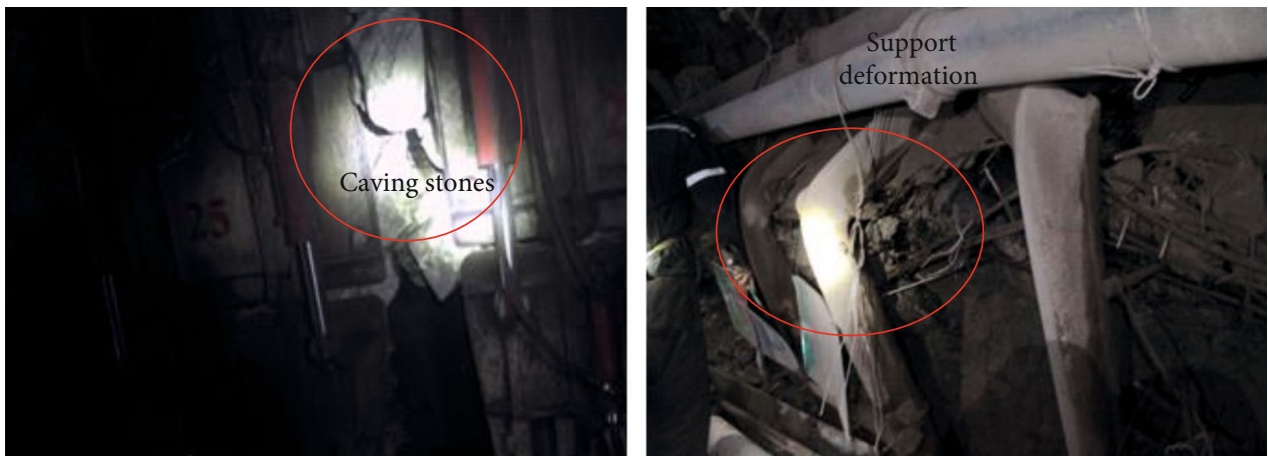

Figure 3: Photos from field investigations.

TABle 1: Coal and gas outbursts during the construction of Paner Coal Mine.

\begin{tabular}{|c|c|c|c|c|c|}
\hline Coal seam & Elevation (m) & $\begin{array}{l}\text { Amount of outburst } \\
\text { coal }(\mathrm{t})\end{array}$ & $\begin{array}{l}\text { Amount of outburst } \\
\text { gas }\left(\mathrm{m}^{3}\right)\end{array}$ & Type & Cause \\
\hline B4-1 & -420 & 56 & 8000 & Outburst & $\begin{array}{c}\text { Changing the form of support and } \\
\text { a leaky roof }\end{array}$ \\
\hline B4 & -470 & 233 & 900 & Extrusion & $\begin{array}{l}\text { Encountering tectonic structures } \\
\text { when uncovering the coal }\end{array}$ \\
\hline B4-2 & -420 & 11.2 & 2000 & Extrusion & $\begin{array}{l}\text { Encountering tectonic structures } \\
\text { when uncovering the coal }\end{array}$ \\
\hline B4-1 & -420 & 22 & 800 & Extrusion & $\begin{array}{l}\text { Encountering tectonic structures } \\
\text { when uncovering the coal }\end{array}$ \\
\hline B4-1 & -420 & 16 & 2400 & Extrusion & $\begin{array}{c}\text { Fissure development, coal uncovering, } \\
\text { and blasting }\end{array}$ \\
\hline
\end{tabular}

\section{Mechanism of the Compound Dynamic Disasters Induced by a Hard Roof}

A hard roof is likely to form a hanging roof in the goaf. The formation, breaking, and migration of this hanging roof exert a mechanical impact in two respects: firstly, the load borne by the hanging roof is transferred from the goaf to the surrounding coal and rock masses, leading to an increase in the stress of the coal and rock masses and, hence, stress concentration. Secondly, the hard roof reaches the hanging limit and breaks, causing shock bump and dynamic load disturbance to the region of high stress concentration. When the dynamic and static loads' superposition satisfies the criteria of the coupled dynamic and static loads inducing rockburst, the rockburst occurs [20-22]. If the coal seam has high gas content and low gas permeability, the impact energy induced by breaking the hard roof works together with the gas expansion energy to induce outbursts, which is the compound dynamic disaster. Therefore, the surrounding rocks' stress distribution features in the coal seam with high gas content and low gas permeability during the mining process are crucial for revealing the compound dynamic disaster's occurrence mechanism under a hard roof condition. Based on the surrounding rocks' spatial structural features, the surrounding rocks' static mechanical model was constructed (as shown in Figure 4).
The load borne by the hanging segment of the hard roof is transferred to the adjacent coal and rock masses. The mechanical equilibrium condition yields:

$$
\int_{-\left(L_{2}+b\right)}^{-b} \sigma_{s y}(x) d x+\int_{0}^{\infty}\left[\sigma_{y}(x)-\sigma_{0}\right] d x=\left(\gamma h_{2}+q\right) L
$$

where $\sigma_{s y}(x), \sigma_{y}(x)$, and $\sigma_{0}$ are the vertical stress distribution functions of the support, solid coal, and in situ stress, respectively; $\gamma$ is the bulk density of the hard roof; and $q$ is the equivalent uniform live load of the overlying strata of the hard roof. The stress distributions of both the support and coal bodies depend on the hard roof's hanging length $L$.

Based on the solid coal stress analysis, the coal body's stress equilibrium equation takes the following form:

$$
\sigma_{s} h_{1}+F_{\mathrm{f}}+F_{\mathrm{b}}=\lambda \sigma_{y}\left(L_{1}\right) h_{1}
$$

where $\sigma_{s}$ is the support strength; $F_{\mathrm{f}}$ and $F_{\mathrm{b}}$ are friction forces acting between the roof and coal body and between the floor and coal body, respectively; and $\lambda$ is the coefficient of lateral pressure.

For the hanging roof structure of goaf formed by hard roof, the first breaking step is obtained in reference [23].

$$
a_{i}=l_{m} w_{i}
$$




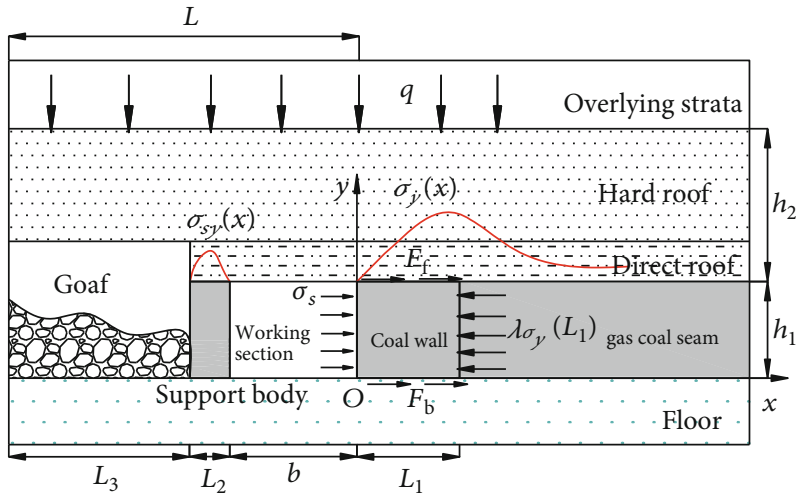

(a) Static analysis of the surrounding rocks under mining

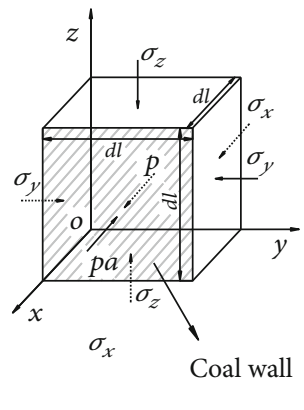

(b) Stress analysis of unit A

FIgURE 4: Mechanical model of the surrounding rocks under a hard roof during mining.

where $a_{i}$ is the first breaking step, $l_{m}$ is the step number; $w_{i}$ is the "edge-length" coefficient of goaf, the subscript is 1, 2, 3, and 4, for a specific goaf; the first breaking step of roof is determined by the step number $l_{m}$, which is calculated as follows:

$$
l_{m}=\frac{h}{1-v^{2}} \sqrt{\frac{2 \sigma_{t}}{q}}
$$

where $h$ is the roof thickness, $\sigma_{t}$ is the tensile strength, and $q$ is the load on roof.

The hanging length of the roof correlates positively with the roof thickness $h$ and tensile strength $\sigma_{t}$. The values of $h$ and $\sigma_{t}$ are relatively large for the hard roof. According to formula (1), as the roof s hanging length $L$ increases, the stress distributions $\sigma_{s y}(x)$ and $\sigma_{y}(x)$ the support and solid coal increase. The static mechanical model shown in Figure 3 applies to both the working face and surrounding rocks of the roadway. When the model represents the working face, the support is in the working face. When it represents the roadway, the support is the entry protection coal-pillar. The former's support strength is much lower than that offered by the solid coal to the roof. Since the support works during the unloading, its stress distribution function $\sigma_{s y}(x)$ is relatively small as the hard roof's hanging area increases. However, the stress distribution function $\sigma_{y}(x)$ of the solid coal increases abruptly in this process. Further analysis of the stress equilibrium represented in formula (2) reveals how rockburst occurs in the working face. As $\sigma_{y}(x)$ increases, the value on the right side of formula (2) increases. To achieve the stress equilibrium, the $\sigma_{y}(x)$ coal body's stress should approach the ultimate strength, leading to the failure of the coal bodies and the release of the elastic deformation energy, thereby inducing rockburst's instability in the coal bodies. The breaking of the hard roof results in shock waves acting on the coal bodies, further producing the coal wall deformation. The increment of the horizontal stress in the coal wall is nonnegligible. Then, formula (2) is reduced to the following form:

$$
\sigma_{s} h_{1}+F_{\mathrm{f}}+F_{\mathrm{b}}=\lambda \sigma_{y}\left(L_{1}\right) h_{1}+\sigma_{d x}
$$

Consider an analytical unit A taken from the exposed surface in the coal body ahead of the working face. Under the working face excavation, there is abrupt unloading of a unidirectional stress in the $x$-direction, and the stress state of unit A is derived (as shown in Figure 3(b)). Upon the moment of coal wall exposure, the wall surface's gas pressure quickly drops to the level equivalent to the ambient gas pressure in the roadway $p_{a}$. The coal bodies, which have already become soft and loose under the tension exerted by the gas seepage pressure, undergo crushing failure. The coal bodies are ejected, and the rockburst goes deeper. Based on the slip line field theory proposed by Zhuang et al. [24], the maximum shear stress is located along the boundary of unit A. Upon the exposure and failure of the coal wall, unit A undergoes an overall slip. The critical condition for the sudden instability is

$\left(p+\sigma_{x}-p_{a}\right)(d l)^{2} \geq 2\left(c+\sigma_{z} \tan \varphi\right)(d l)^{2}+2\left(c+\sigma_{y} \tan \varphi\right)(d l)^{2}$,

where $p$ is the gas pressure inside the coal bodies (MPa); $c$ and $\varphi$ are the cohesive force and internal friction angle of the coal seam, respectively; $p_{a}$ is the ambient gas pressure of the roadway; and $d l$ is the side length of the analytical unit. By performing transposition and simplification of formula (6) and introducing the mechanical indicator $C_{m}$ for the rockburst initiation, we get

$$
C_{m}=\frac{p+\sigma_{x}-p_{a}}{4 c+2\left(\sigma_{z}+\sigma_{y}\right) \tan \varphi} \geq 1 .
$$

It can be seen from formula (7) that the magnitude of rockburst risk is influenced not only by the values of $c$ and $\varphi$ of the coal seam but also by the mining-induced stress and gas pressure. During the coal mine production process, the mining-induced stress and gas pressure control rockburst in regions where the coal seam's hardness varies less significantly.

The breaking of the hard roof occurs suddenly during the coal seam excavation when certain conditions are met. The resulting high stress concentration and impact load on the 
coal bodies produce impact energy. When the coal bodies' stress in the high-stress region exceeds the peak strength, the coal bodies undergo failure, leading to the formation of a plastic deformation region that dissipates energy. The coal bodies near the fracture line in the roof are extruded entirely, thus triggering the rockburst. Deformation and failure of the coal bodies change the gas permeability of the coal bodies. There is a local high-pressure gas accumulation. The shock bump caused by the impact leads to partial desorption of the adsorbed gas. Hence, a greater amount of free gas gushes out from the fissures. The compound dynamic disaster occurs when the gas stored in the plastic deformation region and that desorbed in large amounts from fissures in the surrounding coal, and rock masses gush out rapidly under the joint action of the impact and gas expansion energies.

\section{Stress Evolution Pattern in the Hard Roof}

As shown by the analysis of a hard roof's mechanism inducing the compound dynamic disaster, the mechanical impact generated by the formation, breaking, and migration of the hanging roof, which is formed by the hard roof in the goaf, is the primary influencing factor. Therefore, studying the stress-fissure field's evolution pattern in the hard roof sheds new light on a hard roof's mechanism inducing dynamic disasters in the high gas coal seam. On this basis, more effective control and preventive measures can be elaborated.

4.1. Physical Analog Model. For physical analog modeling, the geometric similarity ratio $C_{\mathrm{D}}$ between the analog parameters and field measured parameters was set to $1: 100$. The similarity ratios of bulk density of the rocks and coal were $C_{\gamma \text {-Rock }}=1: 1.56$ and $C_{\gamma \text {-Coal }}=1: 1$, respectively. Based on a large number of tests and simulations, a complete set of ground pressure similarity theory has been established $[25,26]$. The similarity ratios of model stress, elastic modulus, load, and time were calculated as follows.

In the physical analog modeling, $D$ is defined as length; $\gamma$ is the bulk density; $\delta$ is the displacement; $\sigma$ is the stress; $\varepsilon$ is the strain; $E$ is the elastic modulus; $\sigma_{\mathrm{t}}$ is the tensile strength; $\sigma_{c}$ is the compressive strength; $c$ is the cohesive force; $\beta$ is the internal friction angle; $\nu$ is Poisson's ratio; and $\mu$ is the friction coefficient. According to the similarity theory, the following relationship exists between the physical analog model and geological prototype:

$$
C_{\sigma}=C_{\gamma} C_{\mathrm{D}}
$$

where $C_{\sigma}$ is the stress similarity ratio; $C_{\gamma}$ is the bulk density similarity ratio; and $C_{\mathrm{D}}$ is the geometric similarity ratio.

$$
C_{\mathrm{D}}=C_{\delta} C_{\varepsilon}
$$

where $C_{\delta}$ is the displacement similarity ratio and $C_{\varepsilon}$ is the strain similarity ratio.

$$
C_{\mathrm{E}}=C_{\sigma} C_{\varepsilon}
$$

where $C_{\mathrm{E}}$ is the elastic modulus similarity ratio.
Moreover, since the parameters of the physical analog model (PAM) are equal to those of the geological prototype, the similarity ratios for the strain $(\varepsilon)$, internal friction angle $(\beta)$, friction coefficient $(\mu)$, and Poisson's ratio $(v)$ are equal to unity:

$$
C_{\varepsilon}=1, C_{\beta}=1, C_{\mu}=1, C_{v}=1
$$

According to formulas (8)-(11), there is

$$
C_{\sigma}=C_{\mathrm{E}}=C_{c}=C_{\sigma_{c}}=C_{\sigma_{t}}
$$

Therefore, the similarity ratios of stress and elastic modulus are

$$
C_{\sigma}=C_{\mathrm{E}}=C_{\gamma} C_{\mathrm{D}}=156
$$

The load similarity ratio is

$$
C_{\mathrm{F}}=C_{\gamma} C_{\mathrm{D}}^{3}=1.56 \times 10^{6} .
$$

The time similarity ratio is

$$
C_{\mathrm{t}}=\sqrt{C_{\mathrm{D}}}=10
$$

From the similarity ratio of stress and elastic modulus $C_{\sigma, \mathrm{E}}=1: 156$, the stratum's physical-mechanical parameters for PAM were determined. The initial mix proportions of the analog materials were determined from the similarity theory $[27,28]$. Analog materials used for PAM included fine sand (particle diameter $0.25-0.35 \mathrm{~mm}$ ), lime, and gypsum. After rock fidelity core-taking was carried out on site, collected rocks were processed in the laboratory into standard rock samples meeting the International Association of Rock Mechanics requirements. Eventually, physical and mechanical parameters of rock samples were obtained through uniaxial compression and shear tests. To obtain the appropriate elastic modulus of the PAM material, numerous mechanical tests were performed for the collected samples. The mix ratios of analog materials are shown in Table 2. First, their initial mix proportions were established. Then, weighted mixing was performed for analog materials (fine sand, lime, and gypsum), which were used to prepare the standard columnar specimens. After curing for seven days, the specimens were subjected to mechanical tests. The final mix ratios of analog materials were determined after screening and comparative analysis.

The PAM device dimensions were as follows: length $\times$ width $\times$ height $=3 \mathrm{~m} \times 0.4 \mathrm{~m} \times 2 \mathrm{~m}$. Fine sand was used as aggregate, lime, and gypsum as a cementing agent and water as a bonding agent. Based on the occurrence conditions of the working face 11223 in the Paner Coal Mine, the PAM specification was as follows: length $\times$ width $\times$ height $=3 \mathrm{~m} \times 0.4$ $\mathrm{m} \times 1.3 \mathrm{~m}$. During the PAM experiment, the advancing distance along the working face's strike was $2.2 \mathrm{~mm}$; the distances between the left and right boundaries of the model to the setup entry and stop line were $0.4 \mathrm{~mm}$. A hydraulic loading system was installed above the testing device to 


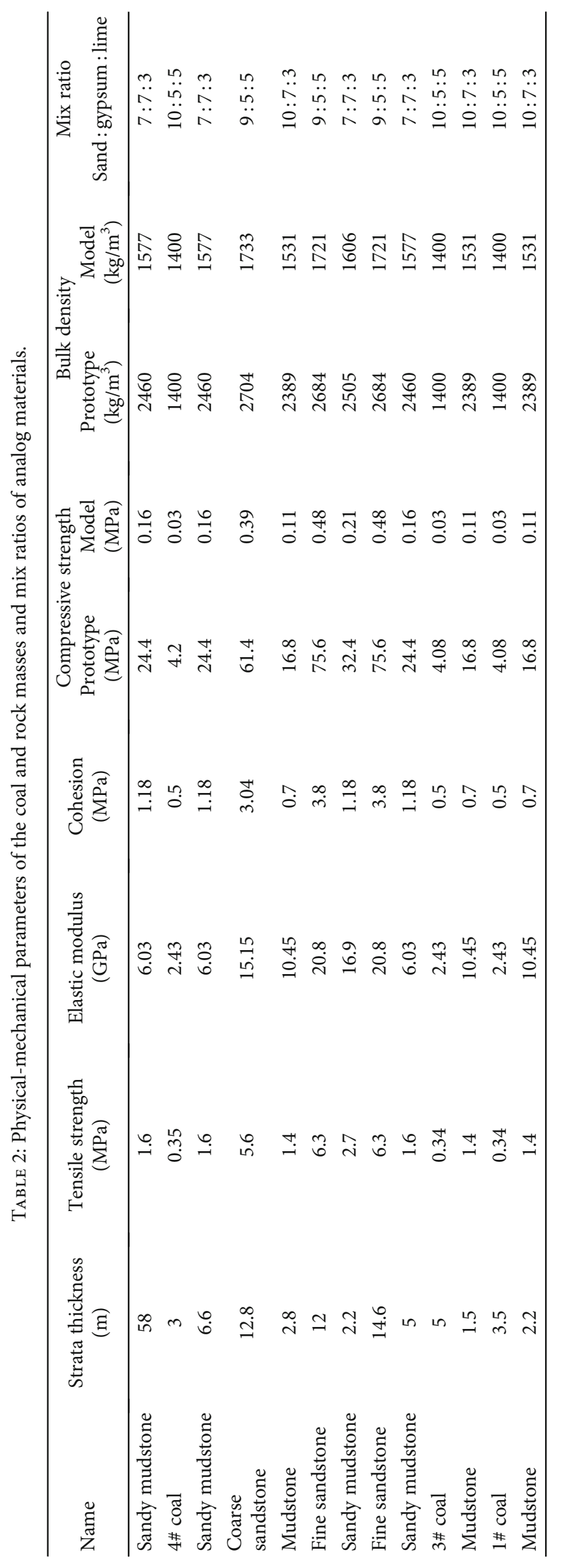




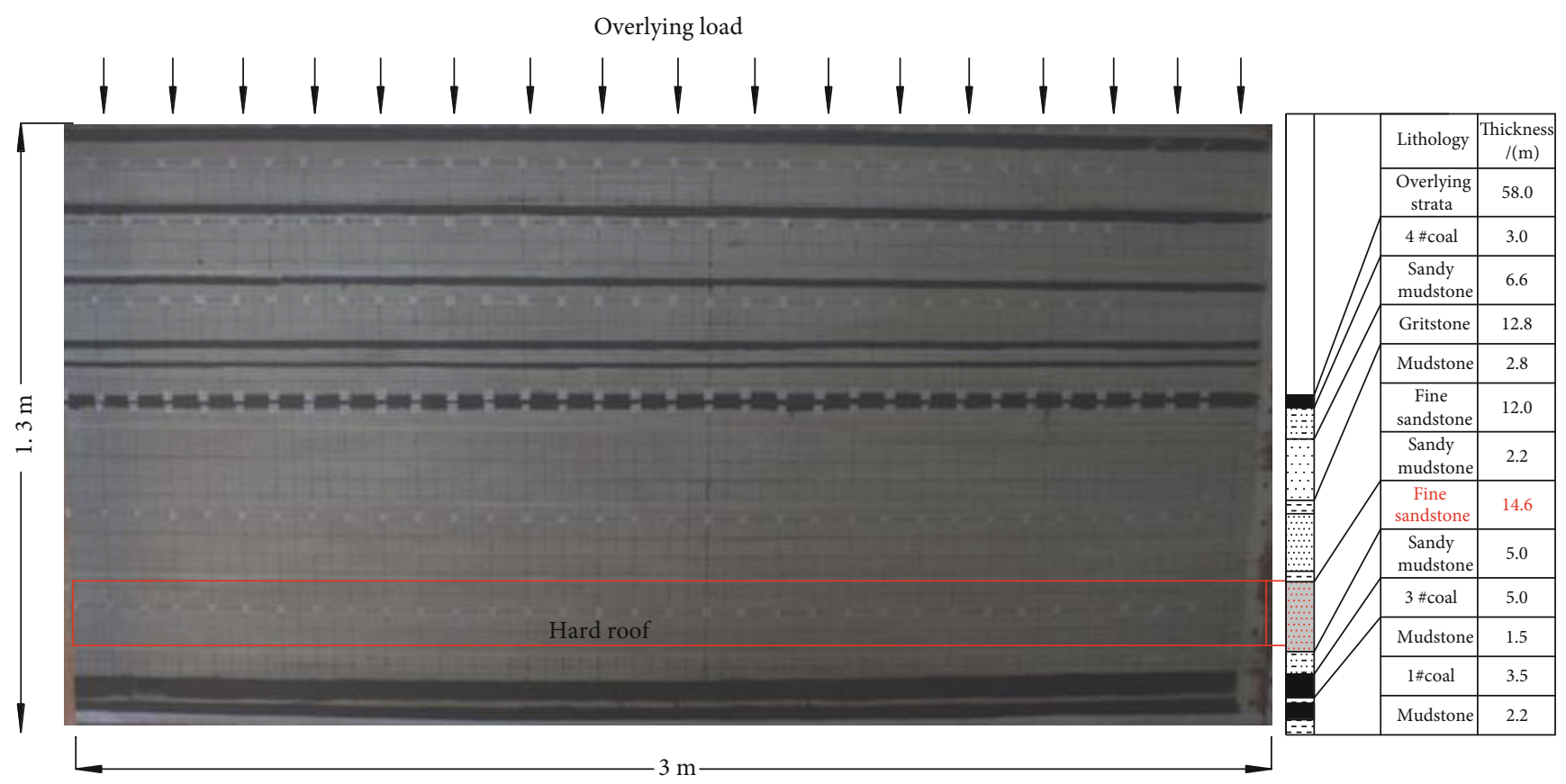

FIgure 5: Physical analog model.

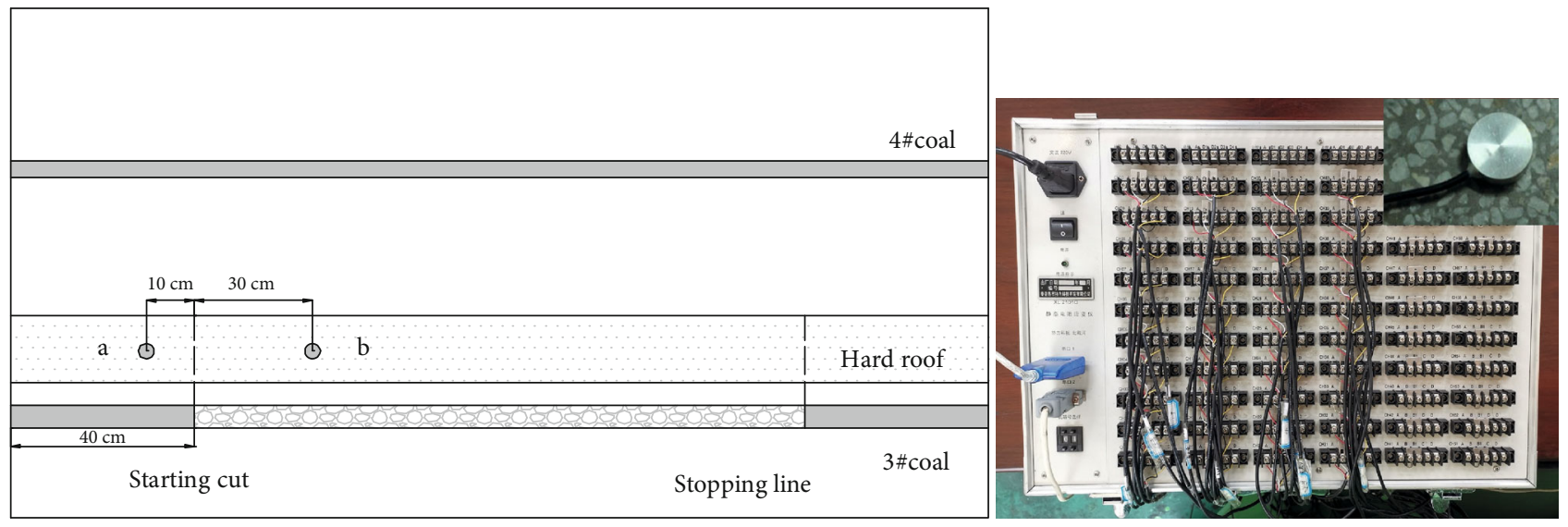

FIGURE 6: Stress sensor and monitoring device.

achieve uniform loading, which partially compensated the overlying stratum's gravity that was not simulated. The thickness and average density of the rock layer above the model were $300 \mathrm{~m}$ and $2500 \mathrm{~kg} \mathrm{~m}^{-3}$, respectively. This rock layer effect on the upper part of the model was reduced to the vertical stress equal to $300 \times 0.025=7.5 \mathrm{MPa}$. The physical model is shown in Figure 5. Based on the time and geometric similarity ratios, each day of the real working face's stoping was equivalent to $2.4 \mathrm{~h}$ of the excavation in a physical analog model. The $3 / 8$ working schedule was adopted in the Paner Coal Mine, with two shifts per day. To be specific, each shift (with the produced excavation of $2.5 \mathrm{~m}$ in the real working face) corresponded to $25 \mathrm{~mm}$ in the PAM excavation. The model's working face advanced by $50 \mathrm{~mm}$ every $2.4 \mathrm{~h}$ (while the real working face was extracted by $5 \mathrm{~m}$ ).

The stress evolution features of the thick hard roof were monitored during the breaking process (as shown in
Figure 6). Two stress measuring points $a$ and $b$ were arranged in the thick hard roof. A BX120-50AA pressure gauge was used as the stress sensor for monitoring stress variations in the coal seam and surrounding rocks. A 7v14 data acquisition system consisting of the data acquisition module, data communication module, computer, and data analysis package was used for data acquisition. The sensor data were directly imported into the computer and subject to dynamic sampling and analysis.

4.2. Analysis of PAM Results. The effect of hard roof breakage on stress distribution was assessed using the data from the stress gauges $a$ and $b$ during the mining process. As shown in Figure 7, the stress gauge $a$ was located on the coal pillar side, where the stress increased, forming a stress concentration region. Along with the coal seam's mining, the stress detected by the stress gauge $a$ increased correspondingly. 


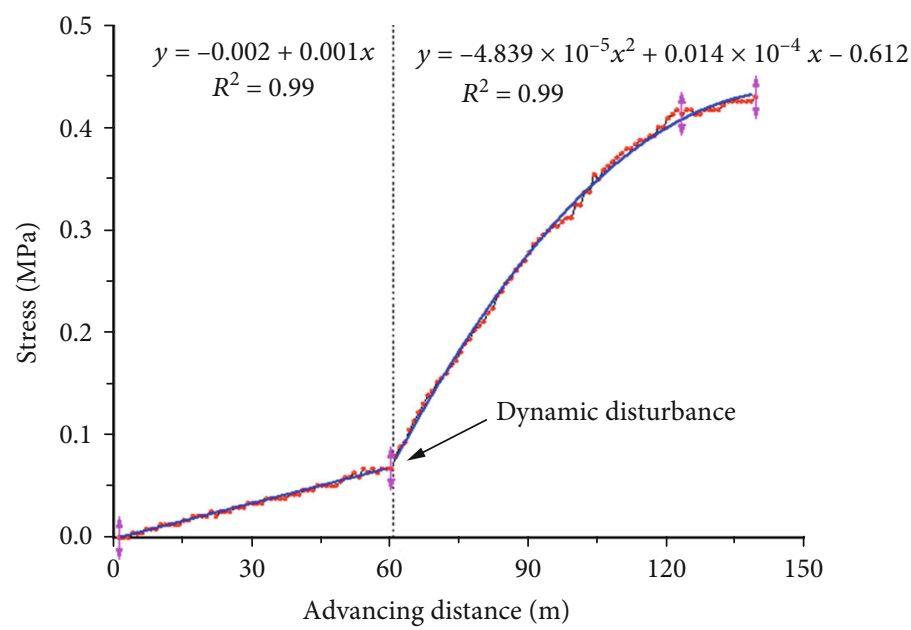

(a) Stress data from the stress gauge $a$

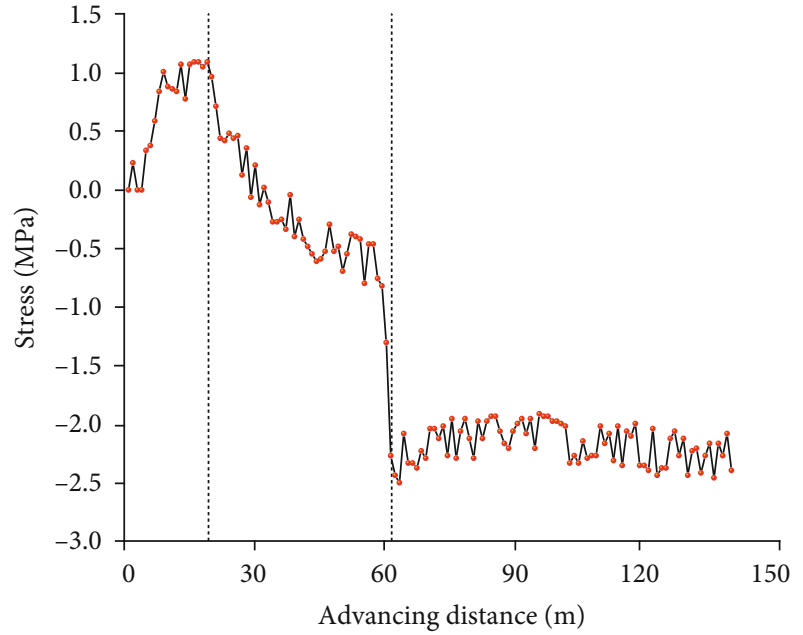

(b) Stress data from the stress gauge $b$

FIgURE 7: Stress field evolution in similar physical simulation.

Under the hard roof condition, the stress distribution process could be subdivided into two stages. At the first stage, before breaking the hard roof, a large amount of elastic energy was accumulated due to the high elastic modulus of the hard roof, while the stress increase rate was low. At the second stage, where the A3 coal seam was extracted to $60 \mathrm{~m}$, the hard rook broke, leading to the immediate release of the elastic energy, an abrupt stress rise, and hence, stress perturbation. At this moment, the rockburst dynamic disaster occurred.

The stress measured by the gauge $b$ first increased and then decreased along with the mining, until the final stabilization. When the coal seam was extracted to $20 \mathrm{~m}$, the stress gauge $b$ was located outside the mining region. The compressive stress of the hard rock strata peaked. Later, the pressure gauge $b$ was located in the goaf, transitioning from compressive stress to tensile stress. When the coal seam was extracted to $60 \mathrm{~m}$, the hard roof broke, leading to an immediate increase in the rock strata's tensile stress, followed by gradual stabilization.

The fissure distribution features were analyzed before and after the breaking of the hard roof. As shown in Figure 8(a), before the first breaking of the hard roof, only the direct roof s caving occurred in the goaf since the hard roof had a high elastic modulus and did not easily break. A hanging roof with a large area appeared; the hanging arc length of the hard roof reaches $50 \mathrm{~m}$. The hard hanging roof formed a simply supported beam structure with coal bodies on both sides. The coal pillars bore a large amount of elastic energy and potential energy accumulated in the stope's overlying strata, and these energies on the two sides. As the working face advanced, the ultimate caving step was reached for the hard roof, and the hard roof broke. As shown in Figure 8(b), after the hard roof broke, the entire hard roof caved in, and the extensive hard roof caving caused intense weighting of the working face. The hanging arc length of the hard roof was $60 \mathrm{~m}$ after the coal seam was further excavated. Later, the hard roof s second breaking occurred, and the hard roof presented massive caving, followed by periodic breaking. The resulting stress redistribution inevitably made on-site support more problematic. On the one hand, the supports had to bear the immediate high-stress impact. On the other hand, the stress concentrated near the coal pillars will be released to produce significant shear stress for the coal wall side. As a result, the masonry beam structure failed, and the supports had to bear the weight of irregular rock blocks that were large in both span and height. This is especially true in the high gas coal seam, where the impact caused by the hard roof breakage will trigger a gas outburst.

4.3. In Situ Monitoring of the Mining-Induced Stress. The A3 coal seam mining effect on the stress distribution in the overlying coal and rock masses was observed. To achieve this goal, eight boreholes were drilled to place stress gauges in the 11224 end-located drainage roadway above the 11223 working face. The boreholes were drilled along the walls of the end-located drainage roadway at an interval of $10 \mathrm{~m}$. The $4 \#$ borehole was directly above the stop line of the 11223 working face. The positions of the $1 \# \sim 8 \#$ boreholes are shown in Figure 8 from left to right. The stress monitoring device was composed of the borehole stress gauge, stress monitoring substation, data acquisition system, and analysis package (as shown in Figure 9). When the 11223 working face advanced to $200 \mathrm{~m}$ away from the stop line, the stress monitoring substation began to capture the gauges' stress variation. The research personnel went underground regularly to export the data from the data acquisition system and analyze them.

As shown in Figure 10, when the 11223 working face advanced to $200 \mathrm{~m}$ from the stop line, the 7 and $8 \#$ stress gauges were at 160 and $170 \mathrm{~m}$ from the initial position of the monitoring, respectively. The stress values showed a slowly increasing trend, with increase rates of 0.0072 and $0.0042 \mathrm{MPa} / \mathrm{m}$, respectively. However, there was no increment at the 5 and $6 \#$ stress gauges that were further away, and both indicated the original stress status. As the working face further advanced to 140 and $120 \mathrm{~m}$, the stress measured 


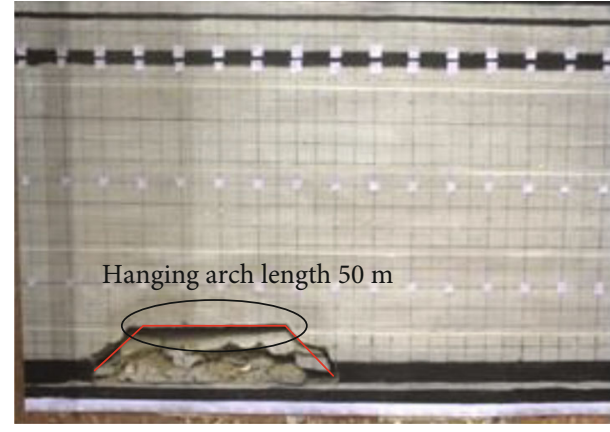

(a) Before the first breaking of the hard roof

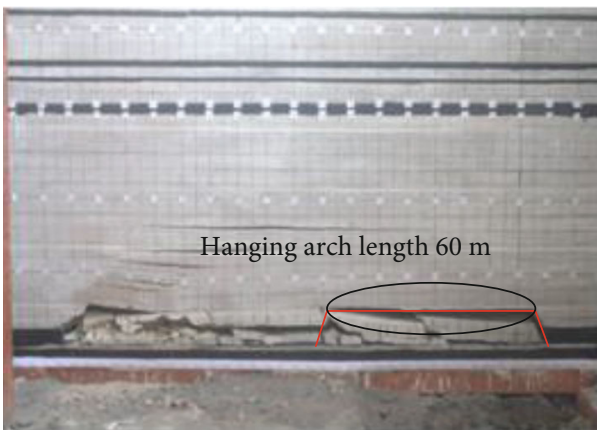

(c) Before the second breaking of the hard roof

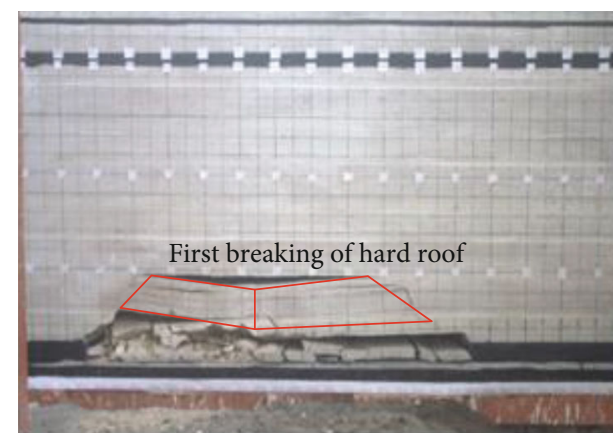

(b) After the first breaking of the hard roof

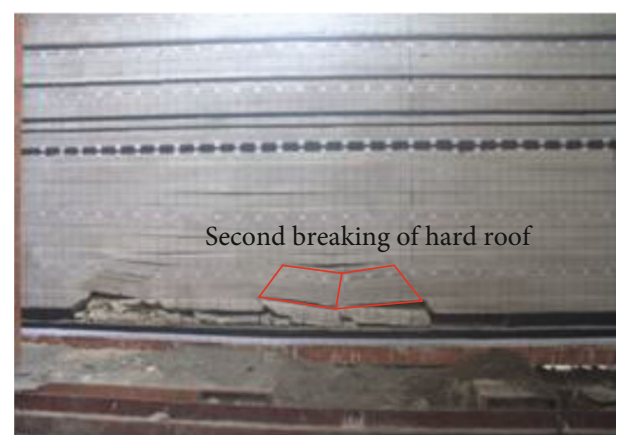

(d) After the second breaking of the hard roof

FIGURE 8: Before and after the breaking of a hard roof.

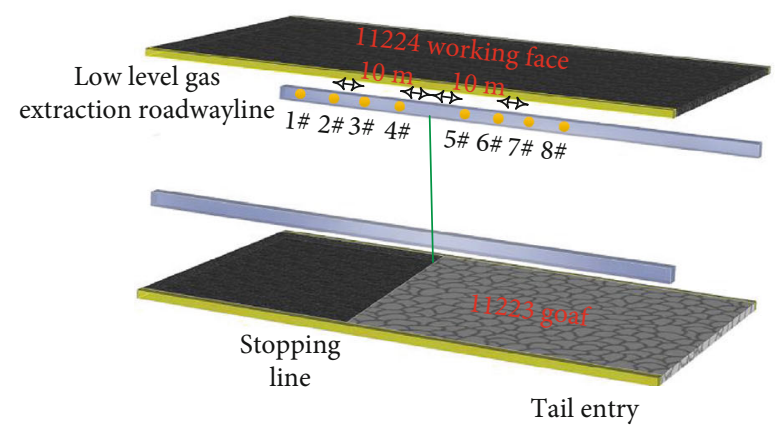

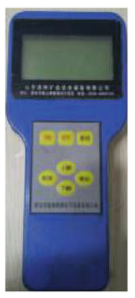

The infrared collector

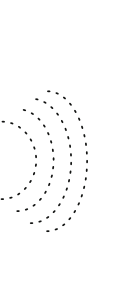

d

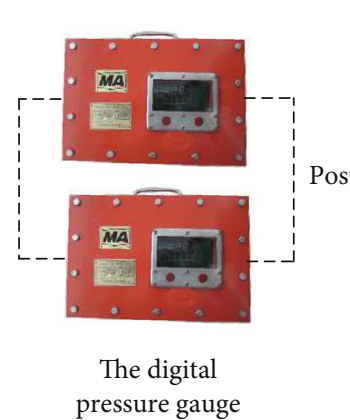

pressure gauge

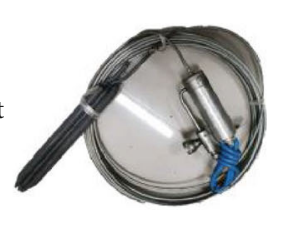

Stress gauge

FIGURE 9: Stress-measuring process using stress gauges, digital pressure gauges, and infrared collector.

by the $6 \#$ and $5 \#$ gauges, respectively, began to increase slowly. The increase rate was 0.0049 and $0.0083 \mathrm{MPa} / \mathrm{m}$, respectively. When the working face advanced to $40-60 \mathrm{~m}$ ahead of the stress gauges, the stress showed a rapidly increasing trend. The increase rate of the $7 \# \sim 5 \#$ stress gauges was $0.033,0.039$, and $0.026 \mathrm{MPa} / \mathrm{m}$, respectively. After peaking, the stress began to decrease to below the level of the original stress. The stress measured by the $4 \# \sim 1 \#$ stress gauges gradually increased as the working face advanced. The stress values continued to increase slowly for some time after stoping. The overlying strata of the working face did not stop migration immediately after stoping, indicating hysteresis in the overlying strata's migration. The peak stress was further analyzed. The stress values at the $8 \# \sim 5 \#$ gauges all peaked, the peak ranging from 0.7 to $1.6 \mathrm{MPa}$. The maximum stress at the $4 \# \sim 1 \#$ gauges fell within the range of $0.2 \sim 0.6 \mathrm{MPa}$, indicating that the four stress gauges on the stop line's left side did not reach the stress concentration peak.

Based on the strata's stress evolution features on the stoping side of the stop line as the working face advanced, the stress variation was subdivided into seven stages. Stage A: in situ stress-the mining-induced stress did not influence this stage, and the region of in situ stress was $170 \mathrm{~m}$ away from the working face. Stage B: slow stress increase-at this stage, the stress increased slowly, and the region of slow stress increase was $80-120 \mathrm{~m}$ wide. Stage C: fast stress increase-the stress rapidly increased to the peak, and the region of fast stress increase was $28-40 \mathrm{~m}$ wide. Stage D: peak stress-at this stage, the peak stress was maintained, and the region of constant peak stress was $10-30 \mathrm{~m}$ wide. Stage E: fast stress decrease-at this stage, the stress rapidly decreased to the level below the original stress, and the region of fast stress decrease was about $10 \mathrm{~m}$ wide. Stage F: unloading-at this 

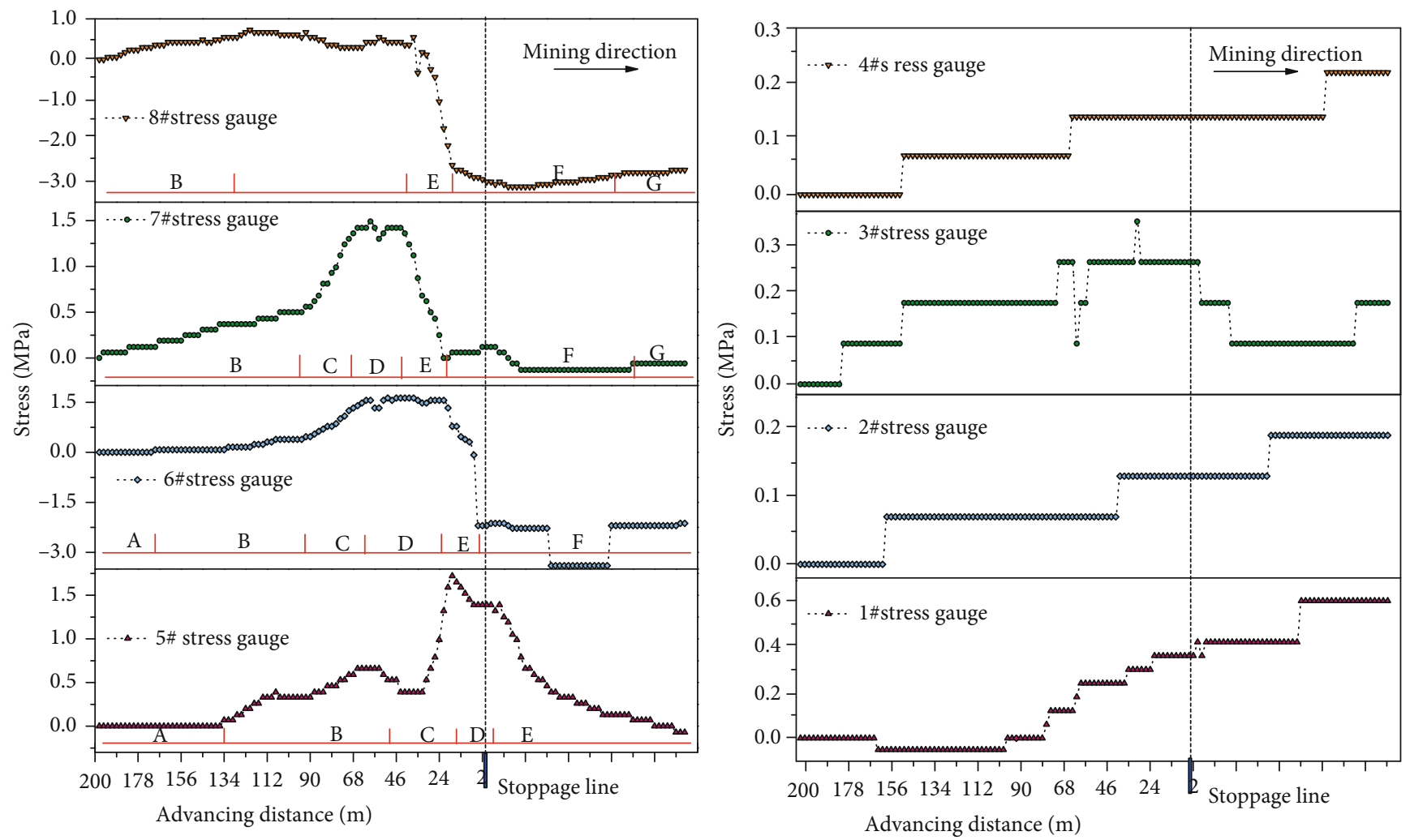

Figure 10: Stress evolution features on both sides of the stop line and working face extraction.

stage, the peak decreased to the level below the original stress. Stage G: stress recovery-at this stage, the strata were reconsolidated, and the stress slowly increased until reaching the in situ stress level.

\section{Preventive and Control Measures}

The compound dynamic disaster of coal and gas outbursts and rockburst involves such processes as deformation and failure of the coal and rock masses, initiation and development of microcracks, desorption of the adsorbed gas, coal body deformation due to gas desorption, dynamic instability of the system, and energy release. Given the above, the preventive and control measures against the dynamic disasters should include the elastic energy dissipation in the coal and rock masses, gas internal energy dissipation, and the plastic zone's energy-dissipating ability increase.

The cross-seam drilling with a high extraction roadway was adopted for the 11223 working face to shield the tail entry tunneling to tackle the coal and gas outburst. The boreholes were arranged in a belt-like manner, with the $7 \times 8$ pattern. Thus, 1480 boreholes were arranged in 185 groups. For the 11223 end-located drainage roadway, the cross-seam drilling was also adopted to shield the head entry tunneling. 1712 boreholes in 214 groups were arranged in a belt-like manner, with the $7 \times 8$ pattern. The borehole diameters in the tail and head entries of the 11223 working face were all $10 \mathrm{~mm}$. The included angle between the along-seam boreholes and dip of the coal seam was $75 \sim 85^{\circ}$. The horizontal distance between the along-seam boreholes was $5 \mathrm{~m}$. The borehole depth was no less than $90 \mathrm{~m}$, and the overlap distance was no less than $10 \mathrm{~m}$ (as shown in Figure 11). The extraction was performed for the underground cross-seam boreholes using the $2 \mathrm{BEF}-72 / 1$ \# line-type extraction pump at the aboveground permanent pump station. For the underground along-seam boreholes, extraction was performed using the 2BEF-72/1\# line-type extraction pump at the aboveground permanent pump station. Thus, the separate measurement of the extraction volume was achieved.

The extraction volume and gas pressure of the A3 coal seam were monitored. The residual gas pressure in the A3 coal seam was $0.17 \mathrm{MPa}$, and the residual gas content was $5.39 \mathrm{~m}^{3} / \mathrm{t}$. During the 11223 working face extraction, the cumulative gas extraction volume was $1178.94 \times 10^{8} \mathrm{~m}^{3}$, and the gas extraction rate was $46.3 \%$. The risk of coal and gas outburst in the A3 coal seam was eliminated, thereby ensuring the coal mine's safe and high-efficiency production.

The deep-hole advanced presplitting blasting technology was applied to solve the hard roof problem, reducing the hanging arc length of the hanging roof and dissipating the coal and rock masses' elastic energy; the mined out area is filled with gangue after blasting, supporting the overlying strata, limiting its rotary subsidence, and realizing the control of the movement of hard roof. The calculation formula of effective depth of presplitting blasting [29] is

$$
h=\frac{h_{\mathrm{m}}}{K_{\mathrm{p}}-1},
$$




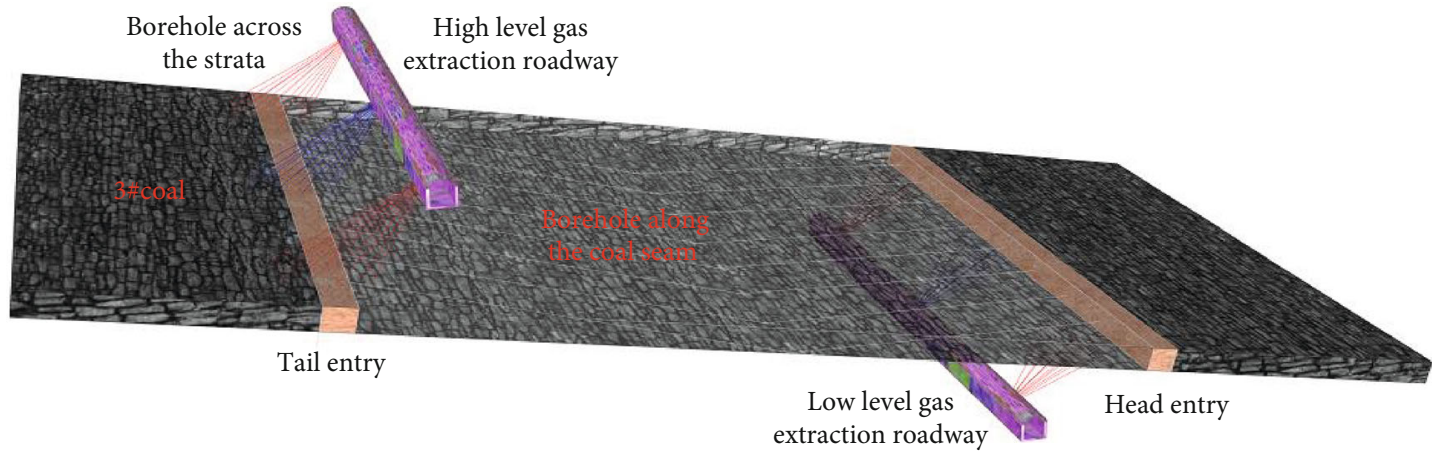

FIGURE 11: Schematic of stereoextraction of gas.

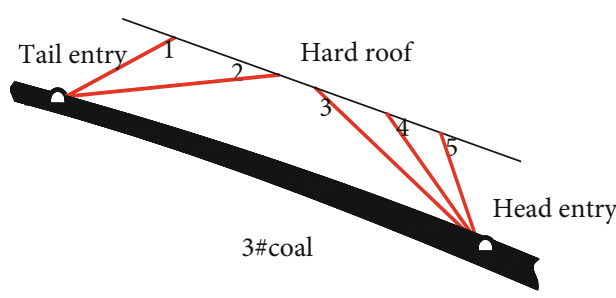

(a) The blast hole horizon

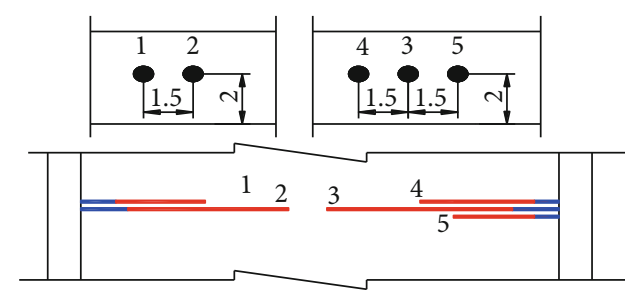

(b) Blast hole parameters

Figure 12: The layout of deep-hole blasting in the long hanging segment of the roof.

TABLE 3: Technical parameters of deep-hole blasting in long hanging roof.

\begin{tabular}{lcccccc}
\hline Roadway & Number & Hole depth $(\mathrm{m})$ & Dip angle $\left({ }^{\circ}\right)$ & Hole diameter $(\mathrm{mm})$ & Charge length $(\mathrm{m})$ & \multicolumn{2}{c}{ Blocking length $(\mathrm{m})$} \\
\hline \multirow{2}{*}{ Tail entry } & $1 \#$ & 27 & 34 & 94 & 21 & 6 \\
& 2\# & 65 & 9 & 94 & 55 & 10 \\
\hline \multirow{3}{*}{ Head entry } & $3 \#$ & 65 & 45 & 94 & 55 & 10 \\
& $4 \#$ & 37 & 65 & 94 & 30 & 7 \\
& $5 \#$ & 30 & 85 & 94 & 24 & 6 \\
\hline
\end{tabular}

where $h$ is blasting thickness; $h_{\mathrm{m}}$ is mining height; $K_{\mathrm{p}}$ is rock fragmentation coefficient. $h_{\mathrm{m}}$ is $5 \mathrm{~m}$, and $K_{\mathrm{p}}$ is 1.26 in the 11223 working face. So the effective blasting thickness is $19.2 \mathrm{~m}$.

According to the effective blasting depth calculated, blasting points were arranged at $75 \mathrm{~m}$ ahead of the cut in 11223 tail entry and head entry; the blasting scheme is shown in Figure 12. Blasting hole parameters are shown in Table 3. In order to ensure the safe initiation of blasting network, two detonators are installed in each hole, and a series blasting network is adopted.

A fully mechanized longwall mining was realized, with 60 four-pillar chock-shield supports installed in the working face. Three support pressure-measuring regions were arranged along the dip direction of the working face. The above 60 supports were installed via a KJ216 digital pressure dynamic monitoring system, which integrated computer monitoring, data communication, and sensor technologies to realize real-time monitoring, transmission, and preservation of the working resistance of the support during the working face advance. According to field measurements, after the blasting of the 11223 working face, the periodic weighting step was $33 \mathrm{~m}$, and the weighting intensity $34 \mathrm{MPa}$. The supports were able to meet the extraction requirements. Upon weighing, the average dynamic load factor of the supports was 1.3 (as shown in Figure 13), indicating a steady weighting. Therefore, the problems of considerable weighting step and weighing intensity were avoided. Upon periodic weighting, the supports were able to provide the needed support resistance for the working face.

\section{Conclusions}

(1) The mechanism of a hard roof in a high gas working face inducing the compound dynamic disaster of rockburst and coal and gas outburst was analyzed. The compound dynamic disaster results from the joint action of the impact energy induced by the breaking of the hard roof and the gas expansion energy. For the region with little variation in the coal seam's hardness, the mining-induced stress and the gas pressure had a controlling effect on rockburst 


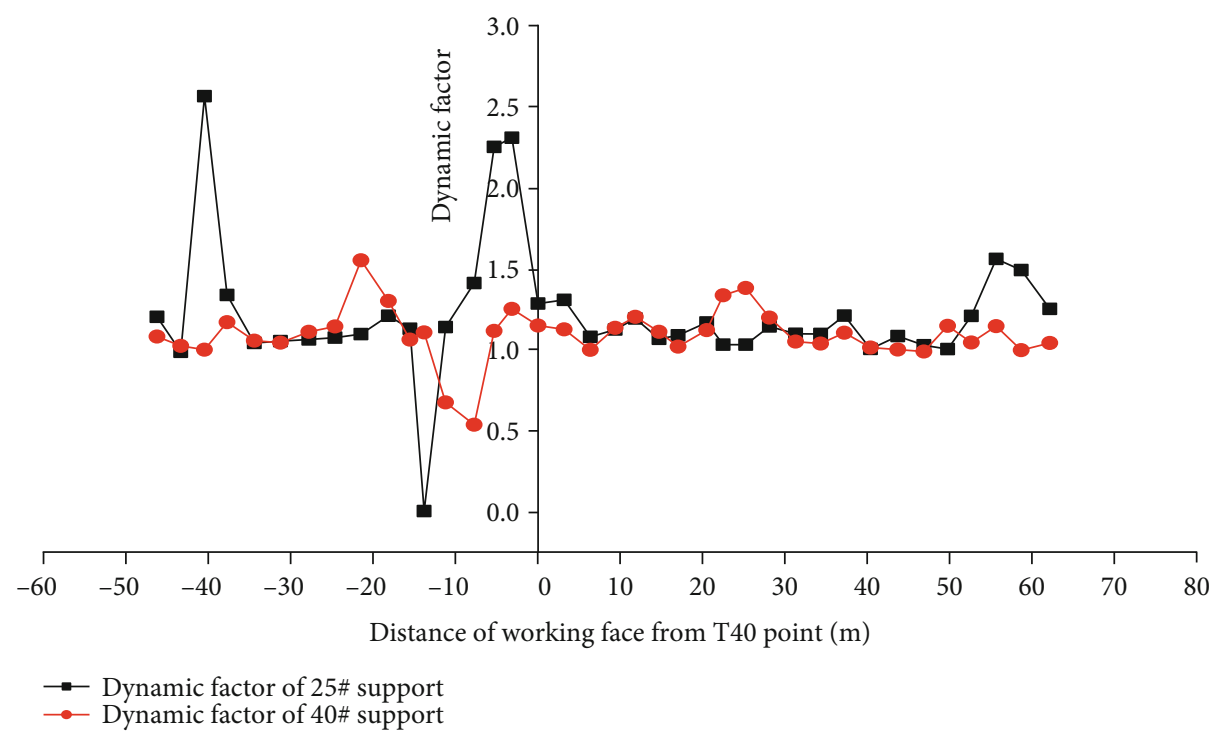

FIGURE 13: Variation curve of the support dynamic load factor.

(2) A physical analog model was built under the geological conditions of the A3 coal seam of the Paner Coal Mine in Anhui province, China. The stress evolution features and fissures before and after breaking the hard roof were analyzed. The stress on the coal pillar side increased immediately after the hard roof breaking. The elastic energy stored in the coal and rock masses and the shock dump incurred by breaking the hard roof were superimposed, producing impact energy and generating the dynamic impact disaster hazard. The hard roof was less likely to cave in than to form a large area hanging roof. Its breaking would cause intense weighting of the working face

(3) In situ monitoring was performed to determine the influence of the A3 coal seam's mining on the overlying strata's stress distribution. Based on the stress evolution features in the strata on the stoping side of the stop line as the working face advanced, the stress variation was subdivided into seven stages

(4) Synergistic stereoextraction integrating cross-seam and along-seam drilling was employed to address gas accumulation in the working face. Deep-hole advanced presplitting blasting technology was applied to reduce the hanging arc length of the hanging roof and to dissipate the elastic energy in the coal and rock masses. This method can effectively reduce the risk of compound dynamic disasters caused by a hard roof

\section{Data Availability}

The test data used to support the findings of this study are included within the article. Readers can obtain data supporting the research results from the test data table in the paper.

\section{Conflicts of Interest}

No conflict of interest exits in the submission of this manuscript.

\section{Authors' Contributions}

All the authors listed have approved the manuscript that is enclosed.

\section{Acknowledgments}

This study has been supported by the National Natural Science Foundation of China (51374011) and the State Key Research Development Program of China (2016YFC0801402). The authors are grateful for the supports received by these sources and technicians at the Huainan Mining Industry (Group) Company who performed the drilling tests.

\section{References}

[1] J. H. Fu and Y. P. Cheng, "Situation of coal and gas outburst in China and control countermeasures," Journal of Mining \& Safety Engineering, vol. 24, no. 3, pp. 253-259, 2007.

[2] Q. T. Hu and X. S. Zhao, "Present situation of coal and gas outburst accidents in China's coal mines and countermeasures and suggestions for their prevention," Mining Safety \& Environmental Protection, vol. 39, no. 5, pp. 1-6, 2010.

[3] Y. D. Jiang, Y. S. Pan, and F. X. Jiang, "State of the art re-view on mechanism and prevention of coal bumps in China," Journal of China Coal Society, vol. 39, no. 2, pp. 205-213, 2014.

[4] Z. Wang, G. Z. Yin, and Q. T. Hu, "Inducing and transforming conditions from rockburst to coal-gas outburst in a high gassy coal seam," Journal of Mining \& Safety Engineering, vol. 27, no. 4, pp. 572-580, 2010. 
[5] Y. S. Pan, "Integrated study on compound dynamic disaster of coal-gas outburst and rockburst," Journal of China Coal Societyss, vol. 41, no. 1, pp. 105-112, 2016.

[6] C. Zhang, S. H. Tu, Q. S. Bai, G. Y. Yang, and L. Zhang, "Evaluating pressure-relief mining performances based on surface gas venthole extraction data in longwall coal mines," Journal of Natural Gas Science and Engineering, vol. 24, no. 1, pp. 431-440, 2015.

[7] T. Teng, Y. X. Zhao, F. Gao, J. G. Wang, and W. Wang, "A fully coupled thermo-hydro-mechanical model for heat and gas transfer in thermal stimulation enhanced coal seam gas recovery," International Journal of Heat and Mass Transfer, vol. 125, pp. 866-875, 2018.

[8] K. Wang and F. Du, "Coal-gas compound dynamic disasters in China: a review," Process Safety and Environmental Protection, vol. 133, pp. 1-17, 2020.

[9] Petukhov, Theory and Practice of Preventing Rock Burst, Coal Industry Press, Beijing, China, 1987.

[10] M. T. Zhang, Z. H. Xu, and Y. S. Pan, "A united instabilty theory on coal (rock) burst and outburst," Journal of China Coal Society, vol. 16, no. 4, pp. 48-53, 1991.

[11] T. Li, M. F. Cai, and J. A. Wang, "Discussion on relativity between rockburst and gas in deep exploitation," Journal of China Coal Society, vol. 30, no. 5, pp. 562-567, 2005.

[12] T. Li, T. T. Mei, and G. Q. Li, "Mechanism study of coal and gas outburst induced by rockburst in "three-soft" coal seam," Chinese Journal of Rock Mechanics and Engineering, vol. 30, no. 6, pp. 1283-1288, 2011.

[13] Y. S. Pan, Z. H. Li, and M. T. Zhang, "Distribution, type, mechanism, and prevention of rockburst in China," Chinese Journal of Rock Mechanics and Engineering, vol. 22, no. 11, pp. 18441851, 2003.

[14] L. M. Dou, J. He, and S. Y. Gong, "Case study on microseismic monitoring of goaf water inrush dynamic hazards," Journal of China University of Mining \& Technology, vol. 41, no. 1, pp. 20-25, 2012.

[15] C. P. Lu, L. M. Dou, H. Liu, H. S. Liu, B. Liu, and B. B. du, "Case study on microseismic effect of coal and gas outburst process," International Journal of Rock Mechanics and Mining Sciences, vol. 53, no. 5, pp. 101-110, 2012.

[16] B. Shen, A. King, and H. Guo, "Displacement, stress and seismicity in roadway roofs during mining-induced failure," International Journal of Rock Mechanics and Mining Sciences, vol. 45, no. 5, pp. 672-688, 2008.

[17] A. Lurka, "Location of high seismic activity zones and seismic hazard assessment in Zabrze Bielszowice coal mine using passive tomography," Journal of China University of Mining \& Technology, vol. 18, no. 2, pp. 177-181, 2008.

[18] L. M. Dou, J. He, and A. Y. Cao, "Rock burst prevention methods based on theory of dynamic and static combined load induced in coal mine," Journal of China Coal Society, vol. 40, no. 7, pp. 1469-1476, 2015.

[19] J. Z. Yang and K. G. Zhen, "The mechanism of overburden dynamic disasters and its control technology in top-coal caving in the mining of thick coal seams," Journal of Mining and Safety Engineering, vol. 37, no. 4, pp. 750-758, 2020.

[20] Z. L. Li, L. M. Dou, W. Cai et al., "Investigation and analysis of the rock burst mechanism induced within fault-pillars," International Journal of Rock Mechanics and Mining Sciences, vol. 70, no. 6, pp. 192-200, 2014.
[21] J. He, L. M. Dou, and W. Cai, "Mechanism of dynamic and static combined load inducing rock burst in thin coal seam," Journal of China Coal Society, vol. 39, no. 11, pp. 2177-2182, 2014.

[22] J. He, L. M. Dou, S. W. Wang, and C. H. Shan, "Study on mechanism and types of hard roof inducing rock burst," Journal of Mining \& Safety Engineering, vol. 34, no. 6, pp. 11211127, 2017.

[23] Z. T. Wang and M. G. Qian, "The calculating methods of the first weighting span of main roof," Journal of China University of Mining and Technology, vol. 18, no. 2, pp. 9-18, 1989.

[24] Y. N. Zhuang, X. S. Ma, and L. Jiang, Engineering plastic mechanics, Higher Education Press, Beijing, 1983.

[25] X. P. Lai, P. F. Shan, J. T. Cao, F. Cui, and H. Sun, "Simulation of asymmetric destabilization of mine-void rock masses using a large 3D physical model," Rock Mechanics and Rock Engineering, vol. 49, no. 2, pp. 487-502, 2016.

[26] H. C. Li, Similar Simulation Test of Mine Pressure, China University of Mining and Technology press, Xuzhou, 1988.

[27] G. X. Xie, J. C. Chang, and K. Yang, "Investigations into stress shell characteristics of surrounding rock in fully mechanized top-coal caving face," International Journal of Rock Mechanics and Mining Sciences, vol. 46, no. 1, pp. 172-181, 2009.

[28] X. Q. Zhang, P. L. Gong, K. Wang, J. Li, and Y. Jiang, "Characteristic and mechanism of roof fracture ahead of the face in an LTCC panel when passing an abandoned roadway: a case study from the Shenghua coal mine, China," Rock Mechanics and Rock Engineering, vol. 52, no. 8, pp. 2775-2788, 2019.

[29] M. G. Qian and P. W. Shi, Mine Pressure and Strata Control, China University of Mining and Technology Press, Xuzhou, 2010. 